\title{
Corpos abalroados / Palavras suspensas
}

\section{Alexandra Moreira da Silva}
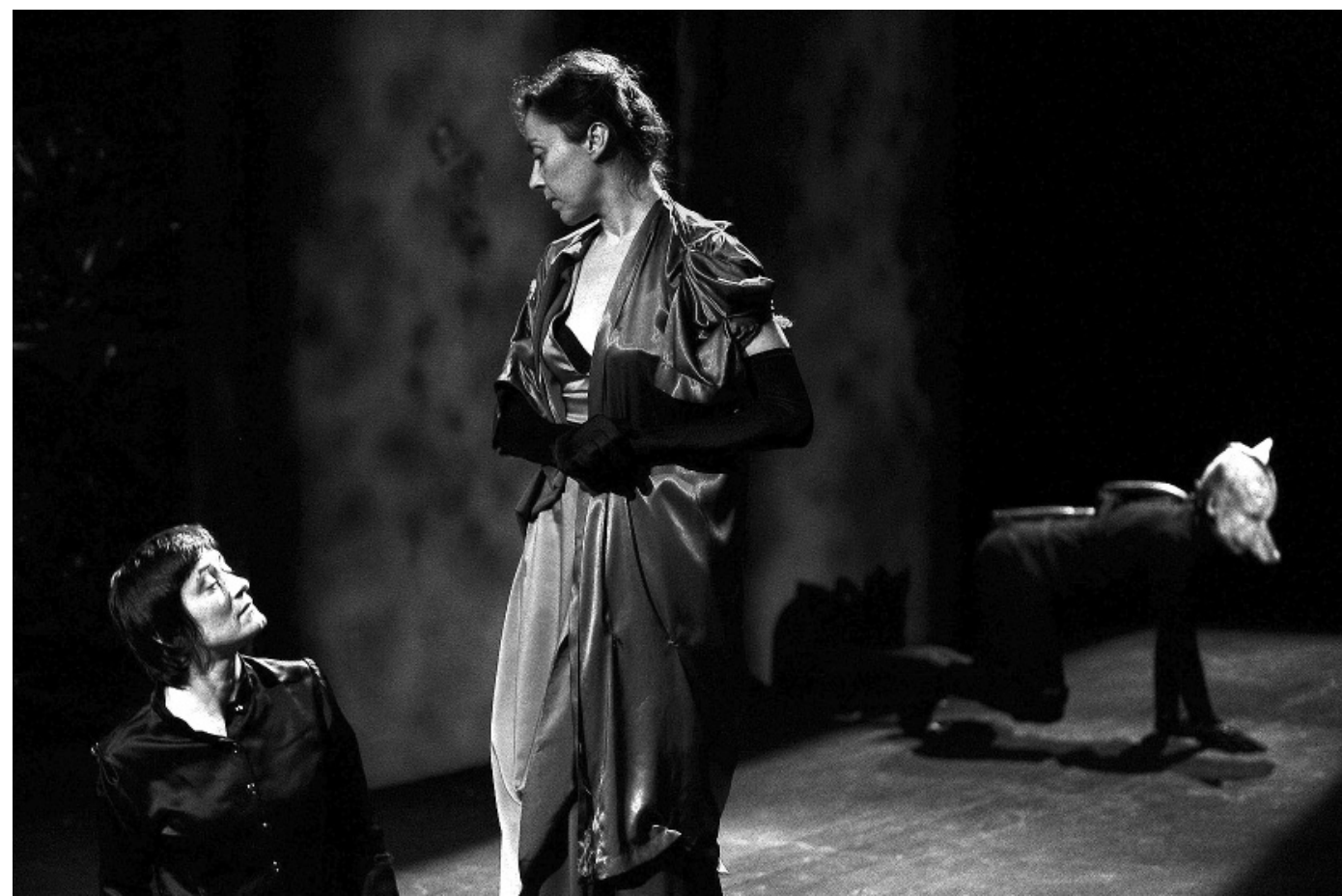

Mulheres profundas

Animais superficiais,

de Howard Barker,

enc. Rogério de Carvalho,

As Boas Raparigas..., 2010

(Carla Miranda

e Maria do Céu Ribeiro),

fot. As Boas Raparigas.

1. B / B (de Barker e de Boas...)

1998, As possibilidades. 2000, (Tio) Vânia. 2006, Mãos mortas. 2009, Os europeus. 2010, Mulheres profundas / Animais superficiais. Há já vários anos que As Boas Raparigas... nos surpreendem com interpretações irrepreensiveis e perturbadoras de um vasto leque de personagens do não menos perturbador universo de Howard Barker. A surpresa é tanto maior quanto o percurso se adivinha discreto, de uma discrição feita de cumplicidades intensas e seguras (com Rogério de Carvalho, com Paulo Eduardo Carvalho, com Miguel Eloy ou Wagner Borges...), cujo lastro, igualmente intenso e seguro, se traduz em acções concretas: no convite, em 2006, a Howard Barker para assistir, no Porto, ao espectáculo Mãos Mortas - memorável, a conferência do autor a que tive oportunidade de assistir no Estúdio Zero - e na publicação das traduções portuguesas dos textos do autor inglês.

A atribuição de uma das Menções especiais do júri da APCT ao elenco do espectáculo Mulheres profundas / Animais superficiais (encenação de Rogério de Carvalho, tradução de Paulo Eduardo Carvalho, produção As Boas Raparigas..., Porto, 9 de Junho de 2010) talvez não seja, por isso, uma surpresa. Mas é concreta, segura e na sua origem estará, certamente, o intenso entusiasmo com que assistimos às notáveis interpretações de Carla Miranda Maria do Céu Ribeiro e Miguel Eloy.

\section{C / C (de Carla e de Céu)}

Duas mulheres - Strassa, a antiga senhora, e Card, a antiga criada - um cão, um cenário de mudança, de destruição, uma paisagem devastada onde (re)nasce o desejo, a perversão, a violência contida nos corpos hirtos e revelada no excesso da palavra. Corpo, palavra e silêncio estão intimamente ligados, na obra de Howard Barker, e também neste espectáculo. Obedecem ao mesmo ritmo, criam uma partitura simultaneamente lírica, intelectual e visceral onde se cruzam o intimo e o político, numa constante deslinearização da narrativa. 0 elenco de Mulheres profundas... faz uma leitura justíssima desta partitura, aliando rigor e instinto num trabalho de invulgar qualidade quer na composição física (com destaque para Miguel Eloy na inquietante personagem do cão), quer no domínio da palavra ritmada e tensa (ao qual nos habituaram já as muito barkerianas Carla Miranda e Maria do Céu Ribeiro) deixando em suspenso as mais variadas "possibilidades".

Maria do Céu Ribeiro é Strassa, mulher desapossada do seu estatuto, inquieta no seu corpo desejado e desejante, 
Animais superficiais,

de Howard Barker, enc. Rogério de Carvalho,

As Boas Raparigas..., 2010

(Maria do Céu Ribeiro

e Carla Miranda),

fot. As Boas Raparigas.

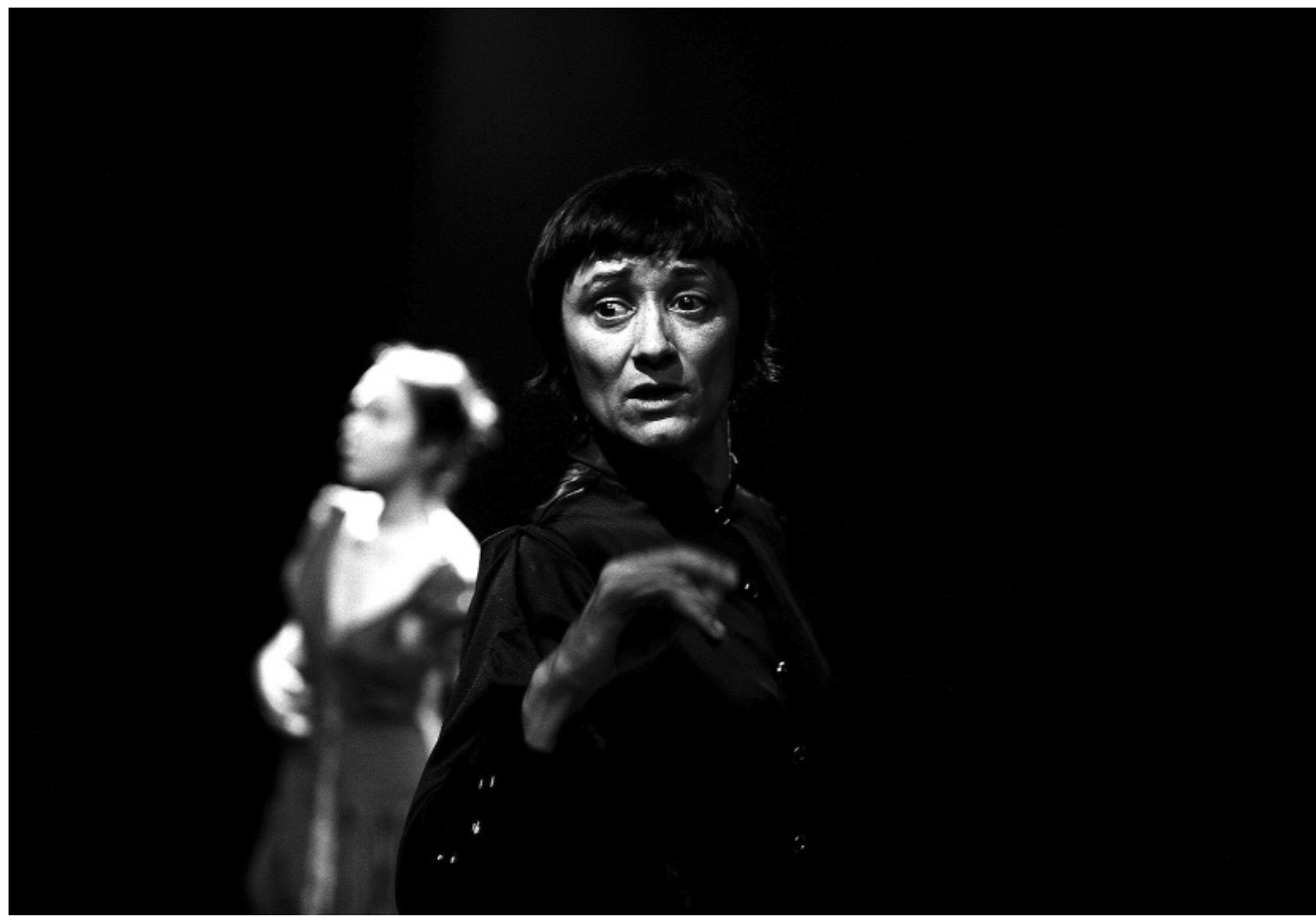

firme na sua voz transgressora, disposta a oferecer-se ao antigo servo (ou à sua mulher? ou aos dois? ou às suas próprias fantasias e imaginação?); "As minhas peças passam-se em paisagens imaginárias", afirma Barker (1998b: 25). Carla Miranda é Card, a esposa do servo, dominada pelo ciúme (do marido? de Strassa? dos dois?), extasiada com a sua nova posição. Mas tudo isto é "nãodito", (talvez inventado? insinuado? sugerido?). Na verdade as duas actrizes mostram-nos, sobretudo, de "onde nos falam", e não tanto aquilo que nos poderiam dizer. E o lugar de onde nos falam é o corpo. 0 corpo transformado na única e mesma fonte do gesto e da palavra, o corpo lugar da erotização da morte e da dor, o corpo que se deixa investir - abalroar - pela palavra, o corpo sensual onde se inscrevem simultaneamente o trauma, a crueldade, o sadismo e a inocência - o "corpo-paisagem". No teatro como refere Howard Barker, só o actor tem o poder de "tornar humanos os elementos ostensivamente inumanos da peça Catastrófica" (1993:111). Conscientes de que a palavra deve ser reveladora, Maria do Céu Ribeiro e Carla Miranda transferem para o espectador toda a tensão poética e psicótica da escrita barkeriana através de uma gestualidade ritualizada, de movimentos controlados, de olhares fixos e inquietos que procuram, talvez, a impossivel suspensão do tempo. Mas o que mais sobressai no trabalho das duas actrizes talvez seja o domínio desse "excesso de linguagem" de que fala o autor britânico, a forma como abalroadas pela palavra, a seguram e mantêm suspensa sem nunca se deixarem intimidar.

\section{E / E (de Encontro e de Eloy)}

Barker parece ser o ponto de encontro de Miguel Eloy e de As Boas Raparigas.... Na verdade, os espectáculos Mãos mortas e Os europeus contaram já com a participação do actor. Em Mulheres profundas/Animais superficiais Miguel Eloy tem uma das suas mais inquietantes e rigorosas interpretações. A personagem do cão intercepta o diálogo das duas personagens femininas. Emissário eventual do antigo servo, o cão vem perturbar e, ao mesmo tempo, acentuar a tensão erótica e fetichista que gradualmente se vai instalando entre as duas mulheres. Da mesma forma que uma voz é um corpo que não vemos, o corpo visivel diz sempre o silêncio da voz. 0 cão "ladra, mia, levanta uma pata, sai, entra, prende e leva peças de roupa", escreve Rogério de Carvalho no programa do espectáculo, ou seja invade de forma ambígua um "mundo de onde os homens talvez tenham desaparecido". Miguel Eloy faz um trabalho 


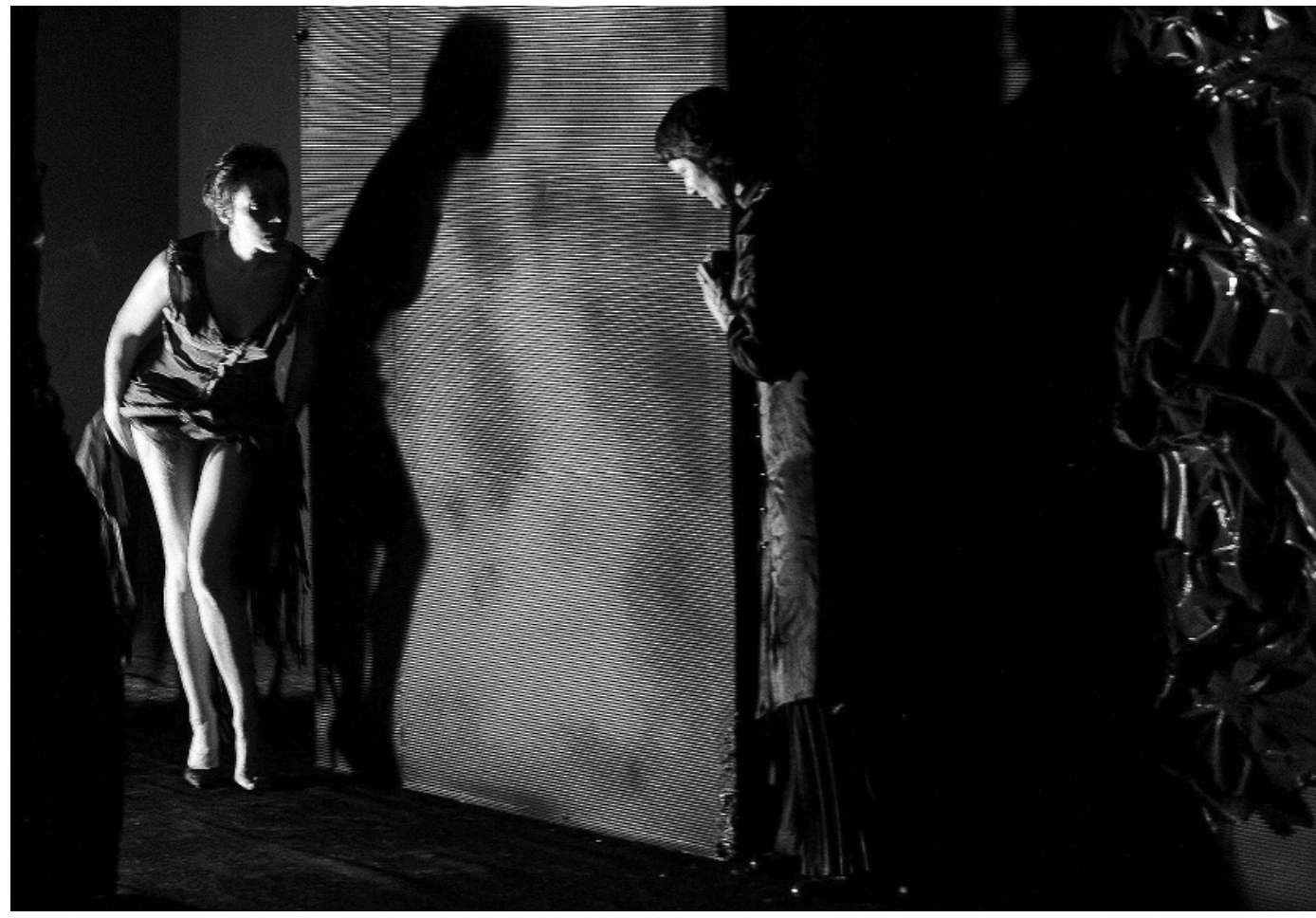

Mulheres profundas/ Animais superficiais, de Howard Barker, enc. Rogério de Carvalho, As Boas Raparigas..., 2010 (< Maria do Céu Ribeiro e Carla Miranda;

v Maria do Céu Ribeiro) fot. As Boas Raparigas.

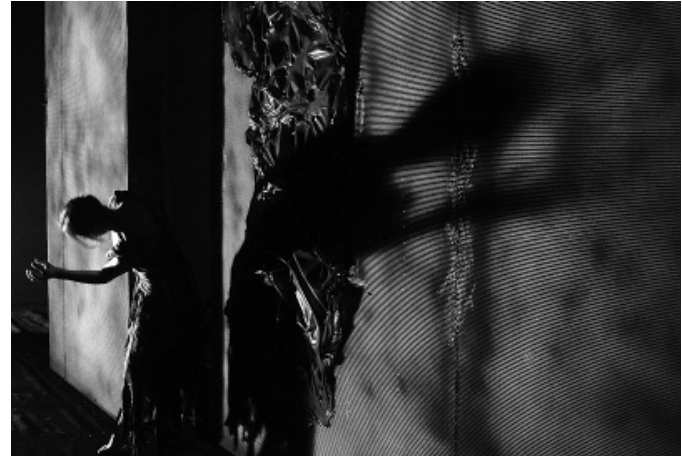

físico irrepreensivel. Graças ao domínio de uma rigorosa codificação do gesto, Eloy reorganiza o olhar do espectador, colocando-se como elemento-chave de uma inusitada triangulação.

\section{D / D (de Desejo e de Decisivo)}

"Este teatro do Não-Reconhecimento é um teatro da emoção, da irracionalidade e da beleza, e não um teatro da ordem, da disciplina e da vontade colectiva (...)" (1993:144); estes actores sabem-no e afirmam-no num gesto vertiginoso de entrega e de revelação, encorajandonos, a nós, público pouco avisado, a seguir a vertigem, a "errar sem mapa", num simples e contagiante desejo de teatro. "D" de Desejo, portanto. E de Decisivo - porque decisivo é, certamente, o trabalho que As Boas Raparigas... e todos os seus colaboradores têm vindo a realizar para a divulgação da obra de Howard Barker em Portugal. Obra densa, musculada, que o elenco de Mulheres profundas / Animais superficiais investe anatómica e organicamente subscrevendo a máxima barkeriana de que "a tragédia é uma forma de arte para aqueles que amam a vida" (1998a: 23).

\section{Referências bibliográficas}

BARKER, Howard (1993), Arguments for a Theatre, Manchester /UK, Manchester University Press.

-- (1998a) "Mon théâtre parle de secret", Alternatives Théâtrales, Howard Barker, n 57, Maio, pp. 24-29.

-- (1998b) "La tragédie: Une forme artistique pour ceux qui aiment la vie", Alternatives Théâtrales, Ibidem, p. 23. 